\title{
Urinary Dipstick Proteinuria Testing: Does Automated Strip Analysis Offer an Advantage Over Visual Testing?
}

\author{
Dane A. De Silva, BMLSc, ${ }^{1,2}$ Anne C. Halstead, MD, FRCPC, ${ }^{1}$ Anne-Marie Côté, MD, FRCPC, ${ }^{3}$ \\ Yasser Sabr, MD, MHSc, ${ }^{2}$ Peter von Dadelszen, MBChB, DPhil, ${ }^{2,4}$ Laura A. Magee, MD, FRCPC ${ }^{4,5,6}$ \\ 'Department of Pathology and Laboratory Medicine, Children's and Women's Health Centre of British Columbia and the \\ University of British Columbia, Vancouver BC
}

${ }^{2}$ Department of Obstetrics and Gynaecology, University of British Columbia, Vancouver BC

${ }^{3}$ Department of Medicine, Université de Sherbrooke, Sherbrooke QC

${ }^{4}$ Child and Family Research Institute, University of British Columbia, Vancouver BC

${ }^{5}$ Department of Medicine, University of British Columbia, Vancouver BC

${ }^{6}$ Department of Specialized Women's Health, British Columbia Women's Hospital and Health Centre, Vancouver BC

\section{Abstract}

Objective: To compare the diagnostic test properties of automated and visually read urine dipstick screening for detection of a random protein:creatinine ratio $(\mathrm{PrCr}) \geq 30 \mathrm{mg} / \mathrm{mmol}$.

Methods: Urine samples were collected prospectively from 160 women attending high-risk maternity clinics at a tertiary care facility. Samples were divided into two aliquots; one aliquot was tested using two different urine test strips, one read visually and one by an automated reader. A second aliquot of the same urine was analyzed for urinary protein and creatinine. Performance of visual and automated dipstick results (proteinuria $\geq 1+$ ) were compared for detection of $\mathrm{PrCr} \geq 30 \mathrm{mg} / \mathrm{mmol}$ using non-dilute urine samples (urinary creatinine $\geq 3 \mathrm{mmol} / \mathrm{L}$ ).

Results: Both urine test strips showed low sensitivity (visual $56.0 \%$ and automated 53.8\%). Positive likelihood ratios were 15.0 for visual dipstick testing $(95 \% \mathrm{Cl} 5.9$ to 37.9$)$ and 24.6 for automated ( $95 \% \mathrm{Cl} 7.6$ to 79.6$)$. Negative likelihood ratios were 0.46 for visual dipstick testing $(95 \% \mathrm{Cl} 0.29$ to 0.71$)$ and 0.47 for automated ( $95 \% \mathrm{Cl} 0.31$ to 0.72$)$.

Conclusion: Automated dipstick testing was not superior to visual testing for detection of proteinuria in pregnant women in a primarily outpatient setting. Sensitivity may depend on the test strips and/or analyzer used.

J Obstet Gynaecol Can 2014;36(7):605-612

Key Words: Automated, pregnancy, proteinuria, urinary dipstick testing, visual

Competing Interests: None disclosed.

Received on December 23, 2013

Accepted on January 16, 2014

\section{Résumé}

Objectif : Comparer les propriétés diagnostiques du dépistage automatisé par bandelette réactive urinaire et du dépistage visuel par bandelette réactive urinaire pour ce qui est de la détection d'un rapport protéines/créatinine ( $\mathrm{PrCr}$ ) aléatoire $\geq 30 \mathrm{mg} / \mathrm{mmol}$.

Méthodes : Des échantillons d'urine ont été prélevés de façon prospective chez 160 femmes fréquentant des cliniques de consultations obstétricales pour patientes exposées à des risques élevés au sein d'un établissement de soins tertiaires. Les prélèvements ont été répartis en deux aliquots : un aliquot a été testé au moyen de deux bandelettes réactives urinaires différentes (une faisant l'objet d'une lecture visuelle et l'autre faisant l'objet d'une lecture automatisée). Un deuxième aliquot utilisant la même urine a été analysé pour ce qui est des taux urinaires de protéines et de créatinine. Le rendement des résultats de la lecture visuelle et de la lecture automatisée (protéinurie $\geq 1+$ ) a été comparé pour ce qui est de la détection d'un $\mathrm{PrCr} \geq 30 \mathrm{mg} / \mathrm{mmol}$ au moyen de prélèvements d'urine non diluée (taux urinaire de créatinine $\geq 3 \mathrm{mmol} / \mathrm{l}$ ).

Résultats : Les deux bandelettes réactives urinaires ont présenté une faible sensibilité (lecture visuelle : $56,0 \%$ et lecture automatisée : $53,8 \%$ ). Les rapports de vraisemblance positifs ont été de 15,0 pour le dépistage visuel par bandelette réactive urinaire (IC à $95 \%, 5,9$ - 37,9) et de 24,6 pour le dépistage automatisé par bandelette réactive urinaire (IC à $95 \%, 7,6$ - 79,6). Les rapports de vraisemblance négatifs ont été de 0,46 pour le dépistage visuel par bandelette réactive urinaire (IC à $95 \%$, $0,29-0,71$ ) et de 0,47 pour le dépistage automatisé par bandelette réactive urinaire (IC à $95 \%, 0,31-0,72$ ).

Conclusion : Le dépistage automatisé par bandelette réactive urinaire ne s'est pas révélé supérieur au dépistage visuel pour ce qui est de la détection de la protéinurie chez des femmes enceintes dans un contexte de services principalement externes. La sensibilité pourrait dépendre des bandelettes réactives et/ou de l'analyseur utilisés. 


\section{INTRODUCTION}

T esting for urinary protein excretion has become central to the care of all pregnant women, but particularly those who are at increased risk of developing preeclampsia. ${ }^{1}$

There are many options for assessing proteinuria. Random (spot) urine samples may be assessed by dipstick test strips, protein:creatinine ratio $(\mathrm{PrCr})$, or albumin:creatinine ratio; dipstick testing is employed for screening at routine antenatal visits, whereas random urinary $\mathrm{PrCr}$ testing is currently reserved for use as confirmatory testing when urinary dipstick proteinuria is detected or when there is another reason to suspect preeclampsia. Although the 24-hour urine collection has been considered to be the gold standard for confirmation of proteinuria in pregnancy, the recognition that it is cumbersome and frequently inaccurate has promoted enthusiasm for $\mathrm{PrCr}^{2-4}$

Screening for proteinuria by visual analysis of urinary test strips is accepted practice, given its convenience and low cost, even though it has been recognized to lack sensitivity. In a review of six studies involving 1738 women and using a cut-off of $\geq 1+$ for detection of significant proteinuria, measured by either 24-hour urine collection or random $\operatorname{PrCr}$, sensitivity was $55 \%$, with specificity of $84 \% .^{5}$

Diagnostic test performance of visually read dipstick proteinuria measurement may be improved with use of an automated test strip reader. In theory, automation may also reduce subjectivity; nevertheless, published sensitivities (41\%, $82 \%,{ }^{7} 90 \%,{ }^{8}$ and $100 \%{ }^{9}$ ) and corresponding specificities $(100 \%, 81 \%, 86 \%$, and $37 \%)$ for automated reading have varied widely, even when the prevalence of proteinuria in the study populations was similar (i.e., $45 \% 0^{7}$ and $48 \% \%^{6}$ ).

The most up-to-date (2010) National Institute of Health and Clinical Excellence (NICE) pregnancy hypertension guidelines recommend use of automated urinary test strip screening as an alternative to visual proteinuria screening, with confirmation by random $\operatorname{PrCr}$ of $\geq 1+.{ }^{10}$

Two studies have compared the diagnostic test properties of automated screening with visually read urinary test strips for proteinuria. ${ }^{7,8}$ Although one study compared test strip screening with 24-hour urinary protein excretion $(\mathrm{g} / \mathrm{d})^{7}$ and the other used 24-hour urinary protein concentration (g/L) as the comparator, ${ }^{8}$ both studies demonstrated superior diagnostic test properties of automated testing compared with visual.

Given the cost of purchasing automated urine test strip readers, we sought to further test the hypothesis that automated testing has diagnostic test properties that are superior to visually read urine test strips for detecting a random urinary $\mathrm{PrCr}$ of $\geq 30 \mathrm{mg} / \mathrm{mmol}$.

\section{METHODS}

This prospective cohort study took place at British Columbia Women's Hospital and Health Centre in Vancouver, BC, from January 27 to March 31, 2011. Consecutive high-risk pregnant women were evaluated. Inpatients were recruited from the assessment room or delivery suite where they were seen for evaluation of hypertension. Outpatients were recruited from our (primarily morning) ambulatory medicine or highrisk obstetric clinics. Women were excluded if they had ruptured membranes or were in labour. Random midstream urine samples obtained as part of normal clinical care were divided into two aliquots to avoid leaching of test strip reagent into the sample, which could interfere with subsequent laboratory assays. The first aliquot underwent point-of-care testing for proteinuria by regular obstetric clinic and hospital staff (nurses and registered nursing assistants) who were familiar with the visual reading method; outpatient staff were specifically trained to use the automated strip reader Urisys 1100 using Chemstrip 10A strips (both Roche Diagnostics, Laval, QC). For visual dipstick proteinuria testing, the Multistix 10SG test strips (Siemens Healthcare Diagnostics, Inc., Tarrytown, NY) were used. These strips categorize proteinuria as negative, trace, $0.3 \mathrm{~g} / \mathrm{L}$, $1.0 \mathrm{~g} / \mathrm{L}$, or $3.0 \mathrm{~g} / \mathrm{L}$, corresponding to negative, trace, $1+$, $2+$, and $3+$, respectively; a positive test was considered to be $\geq 0.3 \mathrm{~g} / \mathrm{L}(\geq 1+)$. The Chemstrip $10 \mathrm{~A}$ strips categorize proteinuria as negative, $0.25 \mathrm{~g} / \mathrm{L}, 0.75 \mathrm{~g} / \mathrm{L}$, and $1.5 \mathrm{~g} / \mathrm{L}$, corresponding to negative/trace, $1+, 2+$, and $3+$, respectively; a positive test was considered to be $\geq 0.25 \mathrm{~g} / \mathrm{L}(\geq 1+)$. Clinicians were unaware of the automated urine test strip results.

The second aliquot of urine was sent to the hospital laboratory, where it was centrifuged at a speed of $1500 \mathrm{rpm}$ for five minutes and then tested in batches. If testing did not occur right away, samples were refrigerated at $4{ }^{\circ} \mathrm{C}$, and tested within the time frame of stability for the assay (i.e., 3 days for protein and 5 days for creatinine). Automated analysis of urinary protein and creatinine (both on Vitros 5,1 FS or Vitros 5600, Ortho-Clinical Diagnostics, Rochester NY) was followed by calculation of the random PrCr.

We calculated sensitivity, specificity, positive and negative predictive values, and positive and negative likelihood 
Table 1. Baseline characteristics of the 109 women providing a non-dilute sample and 51 women providing a dilute sample in the study cohort

$\begin{array}{cc}\text { Women } & \text { Women } \\ \text { who gave a non-dilute } & \text { who gave a dilute } \\ \text { urine sample(s) } & \text { urine sample(s) } \\ n=109 & n=51\end{array}$

Maternal characteristics

Median maternal age, years (interquartile range)

$34(31$ to 36$)$
$50(45.9)$
$3(2.8)$

35 (31 to 37 )

0.261

Primiparous, $\mathrm{n}$ (\%)

25 (49.0)

0.71

Multiple pregnancy, $\mathrm{n}(\%)$

2 (3.9)

0.654

Pregnancy characteristics at the time of urine sampling

Outpatient, n (\%)

$88(80.7)$

$43(84.3)$

0.584

Median gestational age when last urine sample taken, weeks

27 (22 to 34 )

23 (22 to 29.5$)$

0.041

(interquartile range)

On antihypertensive therapy, $\mathrm{n}(\%)$

$23(21.1)$

$9(17.6)$

0.611

Hypertensive disorder at sampling, $n(\%)$

$41(37.6)$

$20(39.2)$

0.781

Pre-existing hypertension only, $\mathrm{n}(\%)$

$17(15.6)$

Pre-existing hypertension with baseline proteinuria, $\mathrm{n}(\%)$

$3(2.8)$

Gestational hypertension without dipstick proteinuria, $\mathrm{n}(\%)$

Preeclampsia (including HELLP syndrome), n (\%)

$12(11.0)$

9 (8.3)

Other medical comorbidities (one/more), n (\%)

49 (45.0)

$18(16.5)$

Two or more medical comorbidities, $\mathrm{n}(\%)$

$14(12.8)$

Diabetes (pre-gestational or gestational), $\mathrm{n}(\%)$

Pre-existing renal disease, $\mathrm{n}(\%)$

$8(7.3)$

Other, ${ }^{*} \mathrm{n}(\%)$

$38(34.9)$

8 (15.7)

0

7 (13.7)

5 (9.8)

$11(21.6)$

-

$3(5.9)$

0.004

2 (3.9)

0.079

0

0.095

$9(17.6)$

0.056

$82(75.2)$

27 (24.8)

$30(58.8)$

0.026

Pregnancy outcome after urine sampling

Delivery at BCWH or postpartum follow-up, $\mathrm{n}(\%)$

$4(4.9)$

Miscarriage or elective termination, $\mathrm{n}(\%)$

$21(41.2)$

0.035

Stillbirth, $\mathrm{n}(\%)$

$2(2.4)$

0

0.035

Placental abruption or other APH, n (\%)

$3(3.7)$

Preterm pre-labour rupture of membranes, $n(\%)$

$1(1.2)$

Chorioamnionitis, n (\%)

38 (37 to 39$)$

Median gestational age at delivery, weeks (interquartile range)

14 (17.1)

Delivery at $<37$ weeks, $n(\%)$

$14(17.1)$

9 (11.0)

$0 \quad 0.999$

$1(2.0) \quad 0.999$

$1(2.0) \quad 0.999$

$0 \quad 0.999$

38 (37 to 39$) \quad 0.688$

$3(5.9) \quad 0.272$

$5(9.8) \quad 0.58$

$3(5.9)$

0.753

Neonatal intensive care unit admission, $n(\%)$

APH: antepartum hemorrhage; BCWH: British Columbia Women's Hospital and Health Centre; HELLP: hemolysis, elevated liver enzyme, low platelet syndrome *Other medical comorbidities included the following:

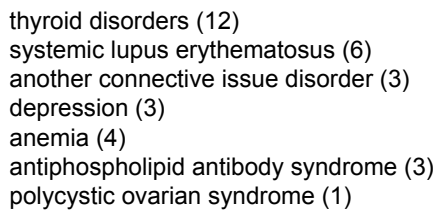

multiple sclerosis (1) immune thrombocytopenia (2)

Raynaud's (1) diabetes insipidus (1) hypercholesterolemia (1) biliary colic (1) deep vein thrombosis (1) polycythemia vera (1) polymyositis (1) scleroderma (1) Addison's disease (1) Crohn's disease (1) celiac disease (1) histiocytosis (1) hepatitis B (1)

hyperaldosteronism (1)

asymptomatic bacteriuria (1)

and/or solitary kidney (1) 
ratios (LR+ and LR-, respectively), with $95 \%$ confidence intervals, for visual and automated test strip proteinuria testing to detect a random $\mathrm{PrCr} \geq 30 \mathrm{mg} / \mathrm{mmol}$, as well as for the lowest $(17 \mathrm{mg} / \mathrm{mmol})$ and highest $(57 \mathrm{mg} / \mathrm{mmol})$ reported cut-offs for random urine $\mathrm{PrCr}$ that correspond to a 24-hour urinary protein of $0.3 \mathrm{~g} / \mathrm{d} .^{3}$ All of these measures are independent of disease prevalence. $\mathrm{LR}+$ and LR - results were interpreted as excellent $(>10$ or $<0.10$, respectively), good (5.1 to 10 or 0.1 to 0.19 , respectively), or fair-poor (2.1 to 5.0 or 0.2 to 0.5 , respectively) according to accepted standards. ${ }^{11}$ The proportion of false negatives and false positives for each of the visual and automated reading methods was compared using the non-parametric McNemar's test, with a $P$ value $<0.05$ considered to be statistically significant. The Pearson chi-squared test, Fisher exact test, and Mann-Whitney $U$ test were used to calculate $P$ values where appropriate. The sample size was chosen by convenience, and the study included all consecutive women seen in the clinic $(\mathrm{N}=160)$. The final study sample $(\mathrm{N}=109)$ had greater than $80 \%$ power to detect a $20 \%$ difference in sensitivity between visual and automated strip testing, a difference compatible with the published literature (two-sided alpha, error 0.05; sensitivity of visual method assumed to be $55 \%$ ). ${ }^{5,7}$

This study was part of a large quality improvement project of proteinuria assessment in our tertiary maternity hospital. ${ }^{12,13}$ We included only women who provided nondilute urine samples with urinary creatinine concentration $\geq 3 \mathrm{mmol} / \mathrm{L}$ in our primary analysis. We did this because we observed falsely elevated urinary $\mathrm{PrCr}$ results on dilute urine samples related to our laboratory's proteinuria method, an issue covered in a separate publication. ${ }^{13}$ We chose urinary creatinine concentration as the method to identify dilute urine because the urine test strip specific gravity is a less reliable measure of urinary dilution. ${ }^{14}$ In addition, we performed a sensitivity analysis using only the last sample for each woman.

This study was approved by the University of British Columbia Clinical Research Ethics Board.

\section{RESULTS}

Of the 160 women who provided 233 samples at our hospital over the study period, we included 109 women who provided 163 non-dilute samples at one or more antenatal visits. Seventy-three women $(67.0 \%)$ provided only one sample.

The baseline characteristics of this study cohort of the 109 women who provided a non-dilute random sample when attending the clinic and the 51 women whose samples were excluded because they were dilute are shown in Table 1. Among those who provided a nondilute sample, most had singleton pregnancies, were evaluated as outpatients in the second trimester, and were not on antihypertensive therapy at the time of urine sampling. Almost all of the outpatient clinics were run in the morning. One third had a hypertensive disorder of pregnancy, most commonly pre-existing hypertension. Compared with those who provided dilute samples, women who provided non-dilute samples were at higher risk, in that they had more medical comorbidities (other than a hypertensive disorder of pregnancy, $P=0.004$ ), and delivered at our tertiary perinatal unit $(P=0.035)$. Although the results did not reach statistical significance, women who provided non-dilute samples may also have delivered earlier (and preterm) and had small for gestational age babies.

Of the 163 non-dilute samples from 109 women, 159 $(97.5 \%)$ were evaluated for dipstick proteinuria by visual reading, and all were evaluated for proteinuria by automated reading.

The individual readings for visual and automated urine test strip methods according to the random urine PrCr result from the same (split) urine sample are shown in the Figure (A and B, respectively). Urine test strip proteinuria of $\geq 1+$ was seen in 20 visually read samples $(12.7 \%)$ and 17 samples by automated reading $(10.4 \%)$.

The diagnostic test properties of each urine test strip assessment method are shown in Table 2. The falsepositive and false-negative rates for automated test strip methods (2.2\% and $43.8 \%$, respectively) and visually read test strip methods $(4.4 \%$ and $40.0 \%$, respectively) were not significantly different $(P=0.999$ for sensitivity and $P=0.248$ for specificity). Using a random PrCr cut-off of $30 \mathrm{mg} / \mathrm{mmol}$, the LR- point estimates for each of the visual and automated dipstick methods were "fairpoor" (i.e., 0.2 to 0.5 ). The $\mathrm{LR}+$ point estimates for visual and automated testing were "excellent," but the $95 \%$ confidence intervals overlapped almost entirely. The $\mathrm{LR}+$ was still "excellent" for both visual and automated testing when a random $\mathrm{PrCr}$ cut-off of $57 \mathrm{mg} / \mathrm{mmol}$ was used, but the $95 \%$ confidence intervals again overlapped substantially.

The diagnostic test properties of visual and automated dipstick testing were similar when only the last sample for each woman was used in the analysis (Table 3). The LRpoint estimates were "fair to good" and the LR+ "excellent" for both visual and automated testing, particularly for detection of a random PrCr of $\geq 57 \mathrm{mg} / \mathrm{mmol}$. 
Results of dipstick testing according to random urinary protein to creatinine ratios (PrCr, mg/mmol). A. Visually read urinary dipstick testing according to random urine $\mathrm{PrCr}$ result. B. Automated urinary dipstick testing $(\mathrm{g} / \mathrm{L})$ according to random urine PrCr result. The horizontal dotted line represents a $\mathrm{PrCr}$ of $30 \mathrm{mg} / \mathrm{mmol}$, the current cut-off for detection of $0.3 \mathrm{~g} / \mathrm{d}$ proteinuria.

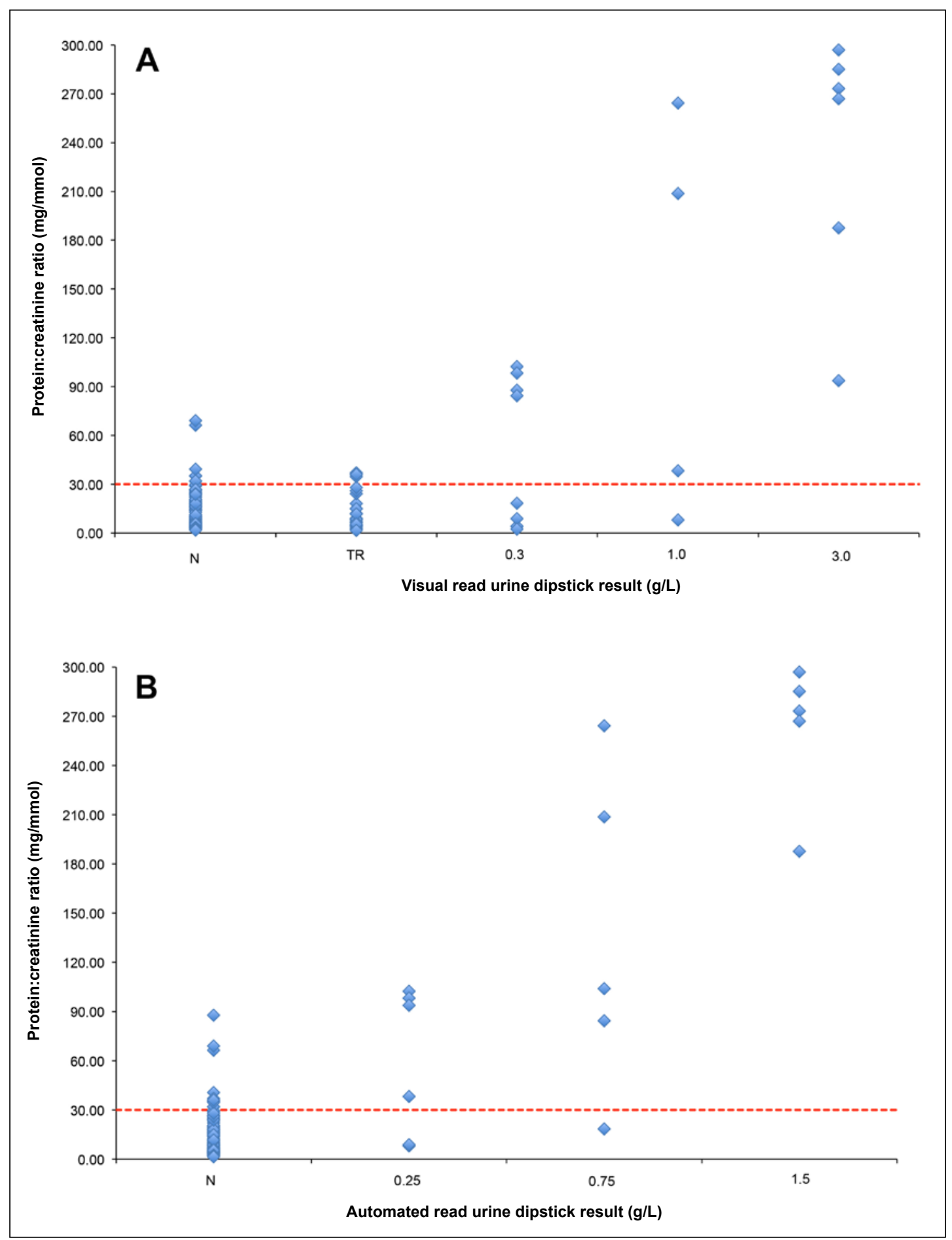

$\mathrm{N}$ : negative; TR: trace 
Table 2. Diagnostic test properties of the visual and automated read urinary dipstick testing methods for detection of a random urinary $\mathrm{PrCr}$ of $30 \mathrm{mg} / \mathrm{mmol}$ (range $17 \mathrm{mg} / \mathrm{mmol}$ to $57 \mathrm{mg} / \mathrm{mmol}$ ) using all non-dilute urine samples

\begin{tabular}{|c|c|c|c|}
\hline & $\begin{array}{l}\text { Random urinary } \mathrm{PrCr} \\
\geq 30 \mathrm{mg} / \mathrm{mmol} \\
(95 \% \mathrm{Cl})\end{array}$ & $\begin{array}{c}\text { Random urinary } \mathrm{PrCr} \geq \\
17 \mathrm{mg} / \mathrm{mmol} \\
(95 \% \mathrm{Cl})\end{array}$ & $\begin{array}{l}\text { Random urinary } \mathrm{PrCl} \\
\geq 57 \mathrm{mg} / \mathrm{mmol} \\
(95 \% \mathrm{Cl})\end{array}$ \\
\hline \multicolumn{4}{|c|}{$\begin{array}{l}\text { Visual read urinary dipstick } \\
\text { ( } n=159 \text { samples })\end{array}$} \\
\hline Sensitivity, \% & 56.0 (37.1 to 73.3$)$ & 26.9 (16.8 to 40.3$)$ & 86.7 (62.1 to 96.3$)$ \\
\hline Specificity, \% & 96.3 (91.6 to 98.4 ) & 95.3 (89.5 to 98.0$)$ & 95.8 (91.2 to 98.1$)$ \\
\hline PPV, \% & 73.7 (48.6 to 89.9 ) & 73.7 (48.6 to 89.9 ) & 68.4 (43.5 to 86.4$)$ \\
\hline NPV, \% & 92.1 (86.0 to 95.8$)$ & 72.9 (64.6 to 79.9$)$ & 98.6 (94.4 to 99.8$)$ \\
\hline LR+ & 15.0 (5.9 to 37.9$)$ & 5.8 (2.2 to 15.1$)$ & 20.8 (9.3 to 46.7 ) \\
\hline LR- & $0.46(0.29$ to 0.71$)$ & 0.77 (0.65 to 0.91$)$ & $0.14(0.04$ to 0.51$)$ \\
\hline \multicolumn{4}{|c|}{$\begin{array}{l}\text { Automated read urinary dipstick } \\
\text { ( } \mathrm{n}=163 \text { samples) }\end{array}$} \\
\hline Sensitivity, \% & 53.9 (35.3 to 71.2$)$ & 25.9 (16.1 to 38.9$)$ & 81.3 (57.0 to 93.4$)$ \\
\hline Specificity, \% & 97.8 (93.8 to 99.3 ) & 97.3 (92.2 to 99.1$)$ & 98.0 (94.2 to 99.3$)$ \\
\hline PPV, \% & 82.4 (55.8 to 95.3 ) & 82.4 (55.8 to 95.3$)$ & 81.3 (53.7 to 95.0$)$ \\
\hline NPV, \% & 91.8 (85.8 to 95.5$)$ & 72.6 (64.5 to 79.5$)$ & 98.0 (93.7 to 99.5$)$ \\
\hline LR+ & 24.6 (7.6 to 79.6$)$ & 9.4 (2.8 to 31.4$)$ & $39.8(12.7$ to 125.0$)$ \\
\hline LR- & 0.47 (0.31 to 0.72$)$ & 0.76 (0.65 to 0.90$)$ & 0.19 (0.07 to 0.53$)$ \\
\hline
\end{tabular}

\begin{tabular}{|c|c|c|c|}
\hline $\begin{array}{l}\text { Last urine sample from } \\
\text { each woman }\end{array}$ & $\begin{array}{c}\text { Random urinary } \mathrm{PrCr} \\
\geq 30 \mathrm{mg} / \mathrm{mmol} \\
(95 \% \mathrm{Cl})\end{array}$ & $\begin{array}{c}\text { Random urinary } \mathrm{PrCr} \\
\geq 17 \mathrm{mg} / \mathrm{mmol} \\
(95 \% \mathrm{Cl})\end{array}$ & $\begin{array}{c}\text { Random urinary } \mathrm{PrCr} \\
\geq 57 \mathrm{mg} / \mathrm{mmol} \\
(95 \% \mathrm{Cl})\end{array}$ \\
\hline \multicolumn{4}{|c|}{$\begin{array}{l}\text { Visual reading of urinary dipstick } \\
\text { ( } n=105 \text { samples) }\end{array}$} \\
\hline Sensitivity, \% & 60.0 (35.8 to 80.2$)$ & 28.1 (15.6 to 45.4$)$ & 90.0 (59.6 to 98.2$)$ \\
\hline Specificity, \% & 95.6 (89.1 to 98.3 ) & 94.5 (86.7 to 97.9$)$ & 95.8 (89.7 to 98.4$)$ \\
\hline PPV, \% & 69.2 (38.9 to 89.6$)$ & 69.2 (38.9 to 89.6$)$ & 69.2 (38.9 to 89.6$)$ \\
\hline NPV, \% & 93.5 (85.8 to 97.3 ) & 75.0 (64.7 to 83.2$)$ & 98.9 (93.2 to 99.9$)$ \\
\hline LR+ & 13.5 (4.8 to 38.3 ) & $5.1(1.7$ to 15.5$)$ & 21.4 (8.0 to 57.0$)$ \\
\hline LR- & $0.42(0.23$ to 0.78$)$ & 0.76 (0.61 to 0.95$)$ & $0.10(0.02$ to 0.67$)$ \\
\hline \multicolumn{4}{|c|}{$\begin{array}{l}\text { Automated reading of urinary } \\
\text { dipstick ( } n=109 \text { samples) }\end{array}$} \\
\hline Sensitivity, \% & 56.3 (33.2 to 76.9$)$ & 26.5 (14.6 to 43.1$)$ & 81.8 (52.3 to 94.9$)$ \\
\hline Specificity, \% & 97.9 (92.5 to 99.4$)$ & 97.3 (90.8 to 99.3$)$ & 98.0 (92.9 to 99.4$)$ \\
\hline PPV, \% & 81.8 (47.8 to 96.8$)$ & 81.8 (47.8 to 96.8$)$ & 81.8 (47.8 to 96.8$)$ \\
\hline NPV, \% & 92.9 (85.3 to 96.8$)$ & 74.5 (64.5 to 82.5$)$ & 98.0 (92.1 to 99.6$)$ \\
\hline LR+ & $26.2(6.2$ to 110.1$)$ & 9.9 (2.3 to 43.5$)$ & 40.1 (9.9 to 162.5$)$ \\
\hline LR- & $0.45(0.26$ to 0.78$)$ & $0.76(0.62$ to 0.93$)$ & $0.19(0.05$ to 0.65$)$ \\
\hline
\end{tabular}




\section{DISCUSSION}

Proteinuria assessment by urinary test strip is an important part of the standard antenatal care of women with low-risk and high-risk pregnancies. In a cohort of pregnant women assessed primarily in an outpatient setting, we found that both visual reading and automated reading of test strips for proteinuria assessment had poor sensitivity (56.0\% and $53.9 \%$, respectively) for the detection of significant proteinuria, indicated by a urinary $\mathrm{PrCr}$ of $\geq 30 \mathrm{mg} / \mathrm{mmol}$. The LR+ was "excellent" but the LR- was only "fair to poor."

The sensitivity for detection of proteinuria on random urine samples using a visual reading method $(56.0 \%)$ was consistent with published values for visual reading tests $(55 \%),{ }^{5}$ but still at the low end of the reported range for automated testing (53.9\% vs. $41 \%$ to $100 \%$, respectively). ${ }^{6-9}$ Our specificities were high for both visually read (95.3\%) and automated dipstick (97.3\%) testing compared with published values (84\% for visual and $37 \%$ to $100 \%$ for automated testing) ${ }^{5-9}$

We are aware of two studies that directly compared the diagnostic test properties of visual dipstick testing with automated testing. ${ }^{7,8}$ For the comparator with test strips, Waugh et al. used 24-hour urinary protein excretion $(\mathrm{g} / \mathrm{d}){ }^{7}$ but Saudan et al. used 24-hour urinary protein concentration $(\mathrm{g} / \mathrm{L}){ }^{8}$ which is not an accepted standard. Waugh et al. recruited only outpatients presenting with de novo hypertension, but we enrolled a more diverse group of highrisk inpatient and outpatient pregnant women, and examined the ability of urinary test strip methods to detect a urinary $\mathrm{PrCr}$ of $\geq 30 \mathrm{mg} / \mathrm{mmol}$ (as used by Phelan et al. for automated dipstick $^{15}$ ), an approach that mirrors NICE guidelines when a urinary dipstick test of $\geq 1+$ proteinuria is detected. ${ }^{10}$

A strength of our study is that we assessed a broad spectrum of high-risk patients with and without significant proteinuria (diagnosed by a random urinary $\operatorname{PrCr}$ of $\geq 30 \mathrm{mg} / \mathrm{mmol}$ ), consistent with published recommendations. ${ }^{10} \mathrm{~A}$ second strength is that urinary dipstick testing was performed by experienced observers who work full-time in a high volume maternity clinic; laboratory staff provided these individuals with specific training on the use and maintenance of the automated test strip reader, consistent with good practice for point of care testing. Third, we assessed the relationship between urinary test strip results of $\geq 1+$ proteinuria and the limits of the reported range over which a random urinary $\mathrm{PrCr}$ has been associated with $0.3 \mathrm{~g} / \mathrm{d}$ of proteinuria by 24 -hour urine collection (i.e., 17 to $57 \mathrm{mg} / \mathrm{mmol}$ ). Finally, our sample size was able to rule out all but a small difference in diagnostic test properties for the visual and automated dipstick testing methods specified; if the very small differences in LR+ were significant, a study population of 6000 women would be required to assess differences.

A limitation of our study is that we recruited women with a low prevalence of proteinuria $(12.7 \%$ by visual and $10.4 \%$ by automated dipstick testing), so we cannot rule out the possibility that inter-observer reliability may be lower (making automated testing more advantageous) at higher urinary protein concentrations. ${ }^{16}$ However, a low prevalence of proteinuria is the reality of outpatient obstetric care, even in a tertiary perinatal unit such as ours which serves a high-risk population. A second limitation is that we excluded 51 women who provided 70 dilute urine samples, so our analysis of visual and automated dipstick testing was performed on $68.1 \%$ of women who provided $70.0 \%$ of the urine samples. Although we cannot exclude the possibility that automated urinary dipstick testing may perform better on dilute urine samples, there is no reason to believe that this would be the case; our choice to restrict analysis to non-dilute samples was based purely on our knowledge that our laboratory urinary protein concentrations were falsely elevated for dilute samples. ${ }^{13}$

Our results apply only to the test strips and the analyzer used in our study. We used the Urisys 1100 analyzer because we were able to adjust (and maximize) sensitivity; as a result, we had to use the Chemstrip 10A strips and could not use the Multistix 10SG strips (the strips used for visual analysis in the clinic) because these must be analyzed using the Clinitek automated reader (Siemens Healthcare Diagnostics, Inc., Tarrytown, NY) which does not have adjustable parameters. ${ }^{7,8}$ It is possible, therefore, that sensitivity with the automated urinary dipstick analysis could have been higher if we had used the Multistix 10SG strips; this was the case when use of Multistix 10SG strips was compared with Chemstrip 10A strips on older automated laboratory strip readers. ${ }^{17}$

\section{CONCLUSION}

We found that the use of an automated urine dipstick reader (Chemstrip 10A on the Urisys 1100 analyzer) did not provide more reliable results than visually read urine dipsticks (Multistix 10SG) in screening for proteinuria in random, non-diluted urine samples from a population of largely outpatient pregnant women screened by clinic staff. These results do not justify the purchase of this automated analyzer, or the time required for maintenance and daily quality control. It is possible, however, that the performance of automated test strip analysis may vary according to the test strips and analyzer used. 


\section{ACKNOWLEDGEMENTS}

We wish to acknowledge the financial support of Ortho Clinical Diagnostics for their unrestricted educational grant used to support this study and the collaboration of the diagnostic ambulatory staff and laboratory staff to conduct this study.

\section{REFERENCES}

1. Magee LA, Helewa M, Moutquin J-M, von Dadelszen P; Hypertension Guideline Committee, Strategic Training Initiative in Research in the Reproductive Health Sciences Scholars. Diagnosis, evaluation, and management of the hypertensive disorders of pregnancy. SOGC Clinical Practice Guideline no.206, March 2008. J Obstet Gynaecol Can 2008;30(3 Suppl 1):S1-48.

2. Côté AM, Firoz T, Mattman A, Lam E, von Dadelszen P, Magee LA. The 24-hour urine collection: gold standard or historical practice? Am J Obstet Gynecol 2008; 199(6):6250-6.

3. Côté AM, Brown M, Lam E, von Dadelszen P, Firoz T, Liston RM, et al. Diagnostic accuracy of urinary spot protein:creatinine ratio for proteinuria in hypertensive pregnant women: systematic review. BM] 2008;336(7651):1003-6.

4. Morris R, Riley R, Doug M, Deeks J, Kilby M. Diagnostic accuracy of spot urinary protein and albumin to creatinine ratios for detection of significant proteinuria or adverse pregnancy outcome in patients with suspected pre-eclampsia: systematic review and meta-analysis. BM] 2012;345:e4342.

5. Waugh JJ, Clark TJ, Divakaran TG, Khan KS, Kilby MD. Accuracy of urinalysis dipstick techniques in predicting significant proteinuria in pregnancy. Obstet Gynecol 2004;103(4):769-77.

6. Dwyer BK, Gorman M, Carroll IR, Druzin M. Urinalysis vs urine protein-creatinine ratio to predict significant proteinuria in pregnancy. J Perinatol 2008;28(7):461-7.
7. Waugh J, Bell S, Kilby M, Blackwell CN, Seed P, Shennan AH, et al. Optimal bedside urinalysis for the detection of proteinuria in hypertensive pregnancy: a study of diagnostic accuracy. BJOG 2005;112(4):412-7.

8. Saudan P, Brown M, Farrell T, Shaw L. Improved methods of assessing proteinuria in hypertensive pregnancy. Br J Obstet Gynaecol 1997;104(10):1159-64.

9. Kyle PM, Fielder JN, Pullar B, Horwood LJ, Moore MP. Comparison of methods to identify significant proteinuria in pregnancy in the outpatient setting. BJOG 2008;115(4):523-7.

10. National Institute for Health and Clinical Excellence. Hypertension in pregnancy: the management of hypertensive disorders during pregnancy. London: NICE; 2014. Available at http://nice.org.uk/CG107. Accessed April 2, 2011.

11. Furukawa TA, Strauss S, Bucher HC, Guyatt G. Diagnostic tests. In: Guyatt G, Rennie D, Meade M, Cook D, editors. Users' guides to the medical literature. 2nd ed. Chicago: McGraw-Hill Education; 2008:419-38.

12. De Silva DA, Halstead AC, Côté AM, Sabr Y, von Dadelszen P, Magee LA. Random urine albumin:creatinine ratio in high-risk pregnancy -is it clinically useful? Pregnancy Hypertens 2013;3(2):112-4.

13. De Silva DA, Halstead AC, Côté AM, Sabr Y, von Dadelszen P, Magee LA. Unexpected random urinary protein:creatinine ratio resultslimitations of the pyrocatechol violet-dye method. BMC Pregnancy Childbirth 2013;13:152.

14. de Buys Roessingh AS, Drukker A, Guignard JP. Dipstick measurements of urine specific gravity are unreliable. Arch Dis Child 2001;85(2):155-7.

15. Phelan LK, Brown MA, Davis GK, Mangos G. A prospective study of the impact of automated dipstick urinalysis on the diagnosis of preeclampsia. Hypertens Pregnancy 2004;23(2):135-42.

16. Kuo VS, Koumantakis G, Gallery ED. Proteinuria and its assessment in normal and hypertensive pregnancy. Am J Obstet Gynecol 1992;167(3):723-8.

17. Dias VC, Moschopedis T, Prosser C, Yatscoff RW. Evaluation of the CLINITEK ATLAS for routine macroscopic urinalysis. Clin Biochem 1996;29(3):217-23. 